\title{
Sclerosing stromal tumor of the ovary: A rare entity with distinctive features
}

\author{
Amal Abd El hafez \\ Pathology Department, Faculty of Medicine, Mansoura University, Dakahlia, Egypt \\ Correspondence: Amal Abd El hafez. Address: Pathology Department, Faculty of Medicine, Mansoura University, \\ El-gomhouria street, Mansoura, Dakahlia, Egypt. Email: amalabdelhafez@gmail.com
}

Received: January 1, 2014

Accepted: February 7, 2014

Online Published: February 12, 2014

DOI : $10.5430 /$ crcp.v1n1p5

URL: http://dx.doi.org/10.5430/crcp.v1n1p5

\begin{abstract}
Sclerosing stromal tumor (SST) is an extremely rare ovarian sex cord-stromal tumor with distinctive pathological features and benign nature. Awareness of such entity is crucial because of its histopathologic similarity with other neoplastic and non-neoplastic lesions of the ovary. In this report, a 29-year-old woman was presented with menstrual irregularities and pelvic pain. She underwent unilateral oophorectomy after detecting a right ovarian mass by ultrasonography. The case was diagnosed as ovarian sclerosing stromal tumor based on clinicopathologic and immunohistochemical features. Differential diagnosis is discussed with review of the literature data.
\end{abstract}

\section{Key words}

Sclerosing stromal tumor, Ovary, Diagnosis, Immunohistochemistry

\section{I ntroduction}

Sclerosing stromal tumor (SST) is an extremely rare ovarian sex cord-stromal tumor with distinctive pathological features and benign nature. Most patients are young, with $70 \%$ of whom being between 14 and 29 years ${ }^{[1]}$. SST arises as a unilateral, well circumscribed mass and its recurrence was not documented. Awareness of such entity is crucial because of its histopathologic similarity with other neoplastic and non-neoplastic lesions of the ovary ${ }^{[2]}$.

In this study, the case of ovarian sclerosing stromal tumor is described and its clinicopathologic and immunohistochemical features are reviewed together with the literature data.

\section{Case presentation}

A 29-year-old woman was presented with menstrual irregularities and pelvic pain. Pelvic ultrasound showed a right ovarian mass $(8.6 \mathrm{~cm}$. in greatest dimension). Unilateral oophorectomy was carried out. Gross examination revealed a smooth, well-encapsulated mass with intact surface. Cut section was solid, grey white to yellow in color and the consistency was rubbery. Neither necrosis nor hemorrhage was observed. 
On histologic assessment, the tumor had a variegated appearance with pseudolobular pattern characterized by alternating hypo and hyper-cellular areas, prominent sclerosis and remarkable small to medium sized thin-walled and ectatic blood vessels imparting hemangiopericytoma-like vascularity (see Figure 1a). Pronounced variation in cellularity was observed with an admixture of spindle collagen-producing cells and polygonal vacuolated cells having small dark eccentric nuclei that may have signet ring appearance (see Figure 1b). The hypocellular areas showed edema but no hyaline plaques or calcification. Mitoses were absent. Immunohistochemistry (IHC) showed diffuse strong nuclear positivity for calretinin (see Figure 2a), and cytoplasmic staining for $\alpha$-Inhibin (see Figure $2 b$ ). The final diagnosis was that of sclerosing stromal tumor of the ovary.
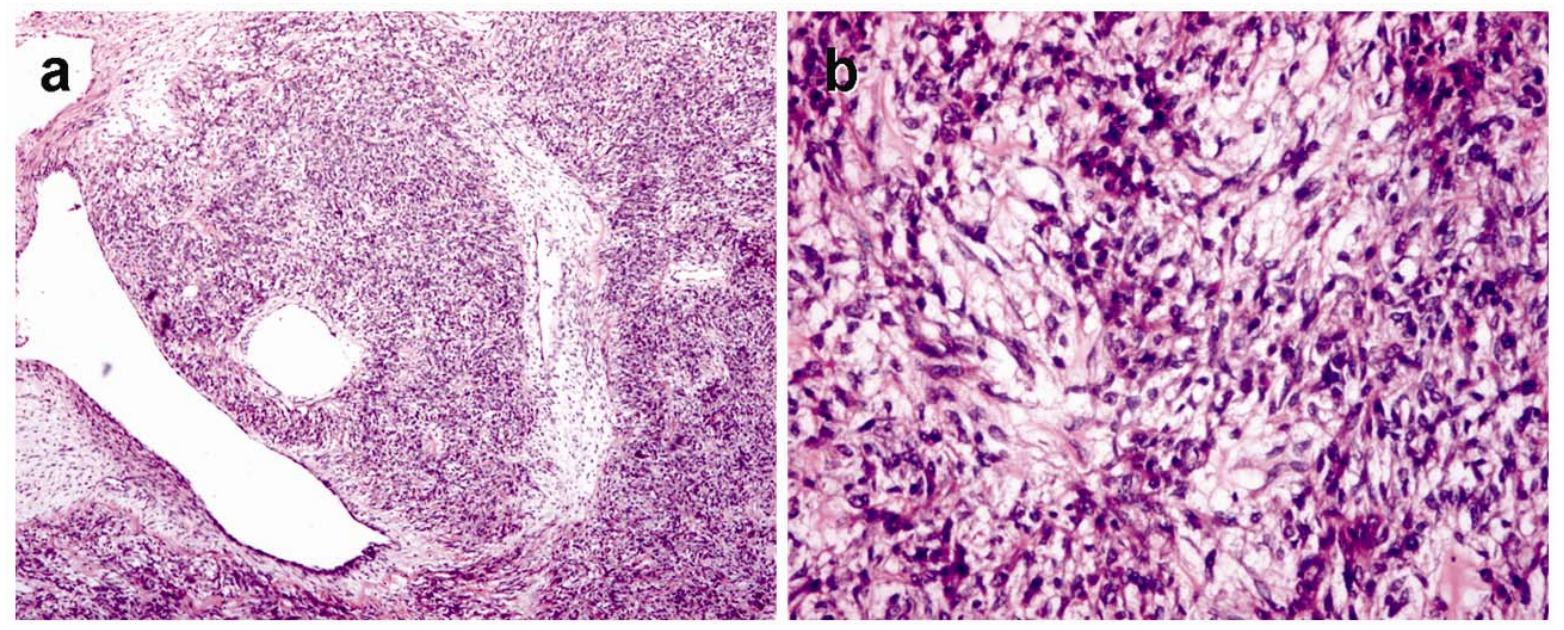

Figure 1. Sclerosing stromal tumorhistopathologic features. (a) Pseudolobular pattern characterized by alternating hypo and hyper-cellular areas and hemangiopericytoma-like vascularity $(H \& E, \times 40)$. (b) Dual cell populations are seen; spindle collagen producing cells\& polygonal cells with vacuolated cytoplasm and small dark eccentric nuclei $(\mathrm{H} \& \mathrm{E} \times 200)$

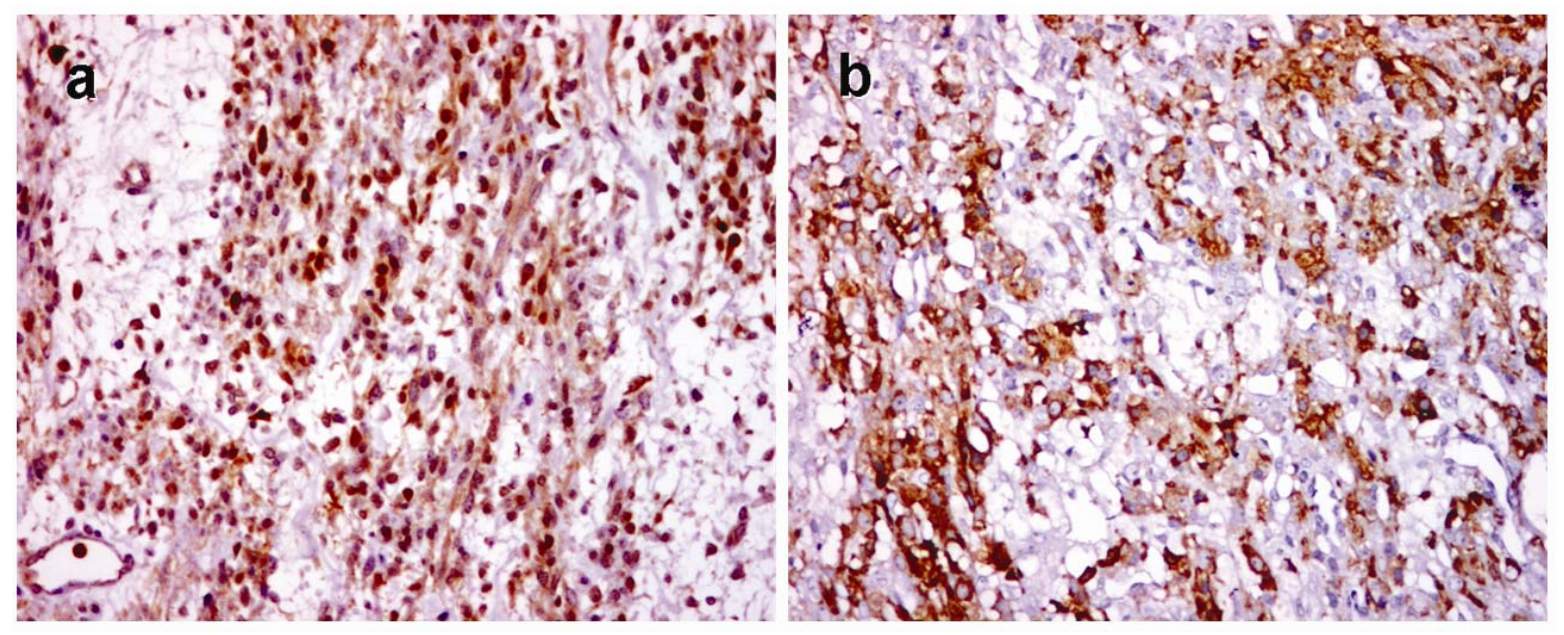

Figure 2. Immunohistochemical profile of sclerosing stromal tumor. Tumor cells show (a) diffuse nuclear immunoreactivity for calretininand; (b) cytroplasmic staining for $\alpha$-inhibin $($ IHC, $\times 200$ )

\section{Discussion}

SST has been described to stem from the perifollicular myoid stromal cells that are normally present in the theca externa. The hormonal activities of these tumors have been presented before as it can be estrogenic or androgenic. These tumors 
synthesize dehydroepiandrosterone rendering irregular menses, amenorrhoea, infertility, precocious puberty or even virilization as the most common presenting symptoms in addition to pelvic pain ${ }^{[3,4]}$.

Characteristic pathological findings of the SST of ovary were observed both macroscopically and microscopically in all the cases reported in literature ${ }^{[4]}$. Moreover, several immunohistochemical markers of the sex-cord stromal tumors were studied in SST and a correlation was observed between the calretinin and $\alpha$-inhibin expressions and the luteinization level of tumor cells ${ }^{[3]}$. In this case, calretinin and $\alpha$-inhibin expressions were detected in the vacuolated tumor cells. In addition, the cells of SST can be positively immunostained for smooth muscle actin and vimentin as well as CD99; and have negative reactivity for S-100 protein and epithelial markers ${ }^{[3,5]}$.

The differential diagnosis of ovarian SSTs encorporates other sex cord-stromal tumors. For instance, fibromas and thecomas could be distinguished from the SST based on the different histopathological findings ${ }^{[5]}$. The pseudolobular pattern composed of hyper-cellular and hypocellular, edematous foci; the prominent vasculature and sclerosis in addition to cellular heterogeneity of the vacuolated cells and spindle shaped fibroblast-like cells are distinctive features being extremely rare in luteinized thecomas and fibromas ${ }^{[2,4]}$. Infrequently, the vacuolated cells and the presence of signet ring cells in association with oedematous stroma may be misdiagnosed as Krukenberg tumors, which could be differentiated by recourse to immunohistochemistry ${ }^{[6]}$. Vascular tumors are contained as well in the differential diagnosis due to outstanding vascularity of SST, however $\alpha$-inhibin positivity implies the diagnosis of SST. Moreover, massive ovarian edema might be confused with SST, however this dilemma can be resolved by finding entrapped histologically normal ovarian tissue within the edematous stroma in massive ovarian edema ${ }^{[2]}$.

The distinct histopathological appearance and immunohistochemistry of SST are important in aiding diagnosis. Surgical resection of the tumor is curative since to date, no local or distant recurrences have been reported in literature.

\section{Disclosure}

No relevant financial affiliations or conflicts of interest to disclose.

\section{References}

[1] Kim JY, Jung KJ, Chung DS et al. Sclerosing stromal tumor of the ovary: MR-pathologic correlation in three cases. Korean J Radiol. 2003; 4(3): 194-199. http://dx.doi.org/10.3348/kjr.2003.4.3.194

[2] Irving JA, Mc Cluggage WG. Ovarian spindle cell lesions: a review with emphasis on recent developments and differential diagnosis. Adv Anatom Pathol. 2007; 14(5): 305-309. http://dx.doi.org/10.1097/PAP.0b013e3180ca8a5b

[3] Park SM, Kim YN, Woo YJ et al. A sclerosing stromal tumor of the ovary with masculinization in a premenarchal girl. Korean J Pediatr. 2011; 54(5): 224-227. http://dx.doi.org/10.3345/kjp.2011.54.5.224

[4] Kaygusuz EI, Cesur S, Cetiner H et al. Sclerosing stromal tumor in young women: clinic pathologic and immunohistochemical spectrum. J Clin Diagn Res. 2013; 7(9): 1932-1935.

[5] Chung JPW, Cheung ECW, Yim SF et al. Hysterectomy for recurrent postmenopausal bleeding revisited: missed sclerosing stromal ovarian tumor. Hong Kong Med J. 2012; 18: 338-339.

[6] Arora R, Gupta R, Dinda AK. Sclerosing stromal tumor: unusual histologic features of a rare ovarian tumor. Indian J Pathol Microbiol. 2008; 51: 445-1447. http://dx.doi.org/10.4103/0377-4929.42520 